\title{
SYNTHESIS AND CHARACTERIZATION OF FeO NANOPARTICLES BY HYDROTHERMAL METHOD
}

\author{
K. Gurushankar ${ }^{1,2,}$, K. Chinnaiah ${ }^{1}$, Karthik Kannan ${ }^{3}$, M. Gohulkumar ${ }^{4}$ \\ and P. Periyasamy ${ }^{5}$ \\ ${ }^{1}$ Laboratory of Computational Modeling of Drugs, Higher Medical and Biological School, South \\ Ural State University, Chelyabinsk-454 080, Russia. \\ ${ }^{2}$ Department of Physics, Kalasalingam Academy of Research and Education, Krishnankoil- \\ 626126, Tamilnadu, India. \\ ${ }^{3}$ Brain Pool Program Postdoctoral Fellow, School of Advanced Materials Science and \\ Engineering, Kumoh National Institute of Technology, 61 Daehak-ro, Gumi-si, Gyeongbuk, \\ Republic of Korea. \\ ${ }^{4}$ Vivekanandha College of Arts and Science for Women, Tiruchengode, Tamil Nadu, India \\ ${ }^{5}$ Department of Physics, Nehru Institute of Engineering and Technology, T.M. Palayam, \\ Coimbatore 641105, Tamilnadu, India \\ ${ }^{\circledR}$ Corresponding Author: gurushankar01051987@gmail.com
}

\begin{abstract}
$\mathrm{FeO}$ nanoparticles were synthesized via hydrothermal method and calcinated at diverse temperatures $\left(400{ }^{\circ} \mathrm{C}, 450\right.$ ${ }^{\circ} \mathrm{C}$, and $500{ }^{\circ} \mathrm{C}$ ). The prepared samples are characterized by various techniques. Crystal size obtained for different annealing temperatures is 21,14 , and $8 \mathrm{~nm}$, respectively. With an increase in temperature for annealing, the intensity of peaks has increased. SEM images note that with normal morphology, the samples have spherical. The average size of particles has obtained by SEM, which are matching with crystalline size obtained by XRD. UV absorbance results at 388, 392, and $399 \mathrm{~nm}$ are confined to the blue emission of wavelength. The edge of the optical bandgap towards the region of moving blue wavelength, which can be recognized at higher temperatures to decrease the FeO nanoparticles bandgap.

Keywords: FeO Nanoparticles, Hydrothermal Method, XRD, SEM with EDX, UV-DRS
\end{abstract}

RASĀYAN J. Chem., Vol. 14, No.3, 2021

\section{INTRODUCTION}

The nanomaterials level is the best progressive at present, both in scientific knowledge and in commercial applications. ${ }^{1-3}$ The enhancement of properties with potential applications, iron oxide is one of the significant pivotal roles in conducting materials today. Due to their applications, several ways have been proposed for the fabrication of $\mathrm{FeO}$ nanoparticles. In recent years, the methods like sol-gel method, ${ }^{4}$ chemical coprecipitation methods, ${ }^{5}$ flow injection methods, ${ }^{6}$ sonochemical deposition methods, ${ }^{7}$ electrochemical method ${ }^{4}$ and hydrothermal $\operatorname{method}^{7}$ are the prominent deposition methods, which are effectively useful for the synthesis of $\mathrm{FeO}$. On the other hand, the significance of $\mathrm{FeO}$ nanostructure morphology in optical properties, and surface characteristics of nanostructure interfaces that determine nano-trapping levels. Therefore, the design and synthesis of $\mathrm{FeO}$ nanoparticles with different structures are very significant. Up to now, enormous research for $\mathrm{FeO}$ nanostructured materials with different morphology and structures synthesized in various forms such as nanoparticles, ${ }^{8}$ nanorods, ${ }^{9}$ and nanosheets ${ }^{10}$ and their features, prospective applications studied intensive manner. Most of the abovementioned synthesized techniques are comparatively expensive and usually need at high temperature, high sensitivity, and application of complex procedures, except the hydrothermal technique, which is more effective, low cost, and rewarding. In the present study, an attempt to made for the synthesis of $\mathrm{FeO}$ nanoparticles by hydrothermal method using Ferric chloride hexahydrate $\left(\mathrm{FeCl}_{3} \cdot 6 \mathrm{H}_{2} \mathrm{O}\right)$ as a precursor and tested at various annealing temperatures for studying different characteristics. 


\title{
EXPERIMENTAL
}

All of the glassware employed in this experiment was acid-washed. The chemical reagents utilized were of the analytical reagent quality, without further purification. Ultra-pure water is employed for dilution and sample fabrication. Ferric chloride hexahydrate $\left(\mathrm{FeCl}_{3} \cdot 6 \mathrm{H}_{2} \mathrm{O}\right)$ and $\mathrm{NH}_{4}$ were attained from Loba Chemie Pvt. Ltd., Mumbai. All the chemicals have a purity of greater than 98 percent.

$\mathrm{FeO}$ nanoparticles were synthesized by using Ferric chloride hexahydrate as a precursor. Initially, $4.75 \mathrm{~g}$ of Ferric chloride hexahydrate $\left(\mathrm{FeCl}_{3} \cdot 6 \mathrm{H}_{2} \mathrm{O}\right)$ was taken to dissolve in $50 \mathrm{~mL}$ of double-distilled water (DDW) and then stirred by magnetic stirring apparatus at room temperature. $40 \mathrm{~mL}$ of aqueous ammonia solution was then progressively added drop-wise into the solution. Further, the resultant solution was continuously stirred for $24 \mathrm{~h}$. At the final stage, the precipitate turned to green color. The ensuing precipitate was filtered and washed numerous times with DDW and ethanol, while green precipitate has dried at $100^{\circ} \mathrm{C}$ for $12 \mathrm{~h}$ in a hot air oven. Samples were annealed for 5 hours at $400^{\circ} \mathrm{C}$ to get the black $\mathrm{FeO}$ nanoparticles. For different annealing temperatures, such as $400^{\circ} \mathrm{C}, 450^{\circ} \mathrm{C}$, and $500^{\circ} \mathrm{C}$, the same procedure was repeated.

\section{General Procedure \\ Synthesis of FeO Nanoparticles}

\author{
$\mathrm{FeCl}_{3} \cdot 6 \mathrm{H}_{2} \mathrm{O}(4.75 \mathrm{~g})+$ ammonia solution $(40 \mathrm{~mL})$ \\ $\downarrow$ \\ Stirred for $24 \mathrm{hrs}$ \\ Washed and filtered with DM water and ethanol \\ Dried for $12 \mathrm{hrs}$ in a hot air oven \\ $\downarrow$ \\ Annealed for 5 hrs at $400^{\circ} \mathrm{C}, 450^{\circ} \mathrm{C}$ and $500^{\circ} \mathrm{C}$ \\ Powder form in $\mathrm{FeO}$ nanoparticles
}

\section{Instrumentation}

X-ray diffraction (XRD), Scanning electron microscopy (SEM), Energy dispersive absorption X-ray analysis (EDAX), and UV-Vis were used for the prepared sample characterization. For identification of the crystalline phase and size of the particles was measured by XRD. Morphological information has been obtained by SEM. EDAX was used to confirm the various elements present in the sample. Absorption and bandgap measurement, UV-DRS spectrum was used. XRD of the samples was recorded with the support of an X-ray diffractometer (Model-D 5000 using with $\mathrm{CuK \alpha} \alpha$ ) consuming wavelength $(\lambda=0.1540 \mathrm{~nm})$. The morphological studies were performed by SEM (JSM 6390 JEOL) and the elemental composition was analyzed by EDX. UV-Vis-NIR spectrophotometer (Perkin-Elmer Lambda 35) was used for recording the optical absorption spectrum.

\section{XRD Analysis}

\section{RESULTS AND DISCUSSION}

Figure-1 explains the XRD patterns of $\mathrm{FeO}$ nanoparticles at varying temperatures $\left(400^{\circ} \mathrm{C}, 450^{\circ} \mathrm{C}\right.$, and $500^{\circ} \mathrm{C}$ ). The XRD patterns display that all the samples are in a single phase and the analyzed structures corresponded to the rhombohedral phase structure (JCDPS card no: 898104). The crystalline intensity peaks are (012), (104), (111), (113), (024), (116), (219), (300), respectively.

The crystalline sample size was determined with the Debye - Scherer formula:

$$
D=\frac{\mathrm{k} \lambda}{\beta \cos \theta}
$$

In this case, $\mathrm{k}$ is the dimensionless shape factor of $0.9, \lambda$ is known as $\mathrm{X}$-ray wavelength, $\beta$ is line broadening at half the maximum intensity (FWHM), and $\theta$ is known as angle of Bragg. FeO nanoparticles have mean crystalline sizes of $22\left(400^{\circ} \mathrm{C}\right), 14\left(450^{\circ} \mathrm{C}\right)$, and $8\left(500^{\circ} \mathrm{C}\right) \mathrm{nm}$ respectively. The crystalline size was decreased when the annealing temperature was increased. 
RASĀYAN J. Chem.

Vol. 14 | No. 3 |1985-1989| July - September | 2021

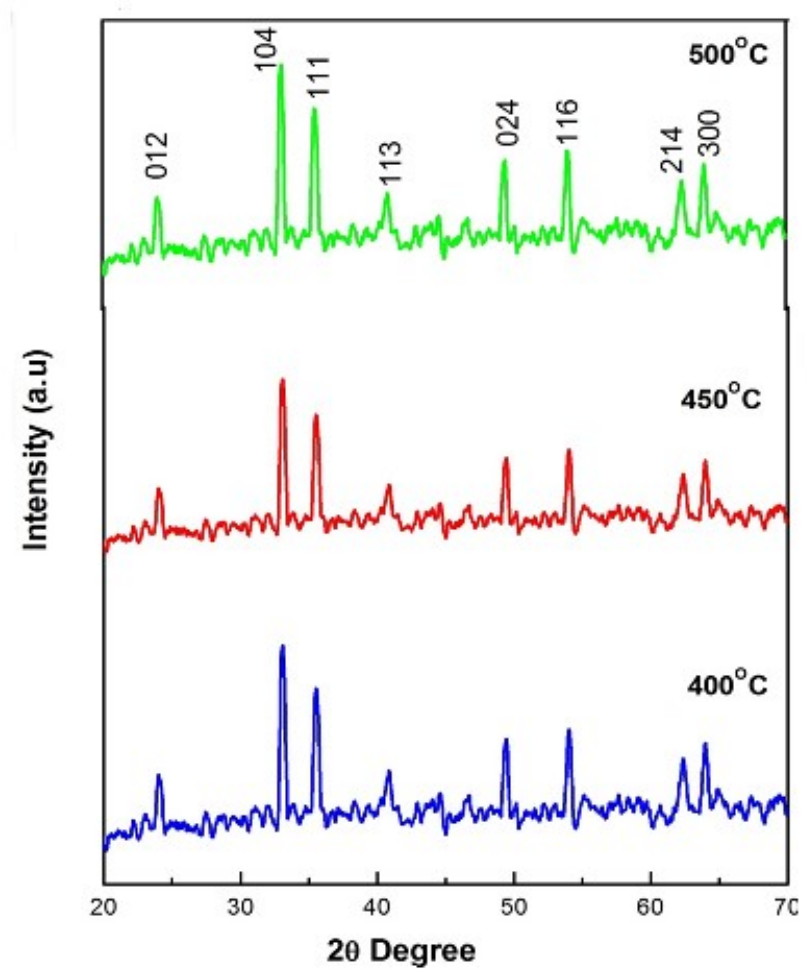

Fig.-1: XRD Spectrum of FeO Nanoparticles at Different Temperature

\section{SEM with EDAX Analysis}

To study morphology and elemental presentation in the samples, SEM and EDAX were used. Fig.-2(b) shows well-oxidized and dense agglomerations reacting to iron oxide nanoparticles. Fe and $\mathrm{O}$ elements were observed in conserved peaks seen in Fig.-2(d). It indicates that the formation of pure $\mathrm{FeO}$ nanoparticles confirmation, without any impurities. The samples are composed of spherical nanoparticles with a standard morphology (Fig.-2(a,c)) and a good correlation between the mean size and the crystalline size obtained by XRD.

\section{UV- Vis Spectroscopy}

Figures-3 and 3a display the UV-Vis spectrum of prepared $\mathrm{FeO}$ nanoparticles. The absorption values were noticed in the range of $300-400 \mathrm{~nm}$. This range of wavelength is confined to blue shift emission. The absorption values were located at $388\left(400^{\circ} \mathrm{C}\right), 392\left(450^{\circ} \mathrm{C}\right), 398 \mathrm{~nm}\left(500^{\circ} \mathrm{C}\right)$. Furthermore, the maximum absorption peak value, due to the existence of a given bandgap, concludes that valence electrons merely consume a particular energy package to overcome the concern-insulated barricade. This may be the logical outcome of expanding the bandgap because it occurs because of the particle size reduction. As well, as the meaning of decreasing particle size and the density of states within the particle is inclined to be distinct, it tends to be discrete to decrease the number of atoms within a particle. Therefore by absorbing at an exact wavelength, valence electrons will mainly be excited than or else, whose energies appear too small to show in the far-infrared region or too large to fall within the X-ray section. This results in a definite peak in the absorbance spectrum of $\mathrm{FeO}$ nanoparticles (300-800 nm). In addition, the absorbance value is significantly higher than that of bulk iron oxide, which means that nanoparticles have a reduced particle size.

The direct optical band gap value of the samples analyzed through the following equation has been correlated with photon energy as well as absorption.

$$
\mathrm{E}(\mathrm{gap})=\mathrm{hv} / \lambda
$$

and

$$
(\alpha h v)=A(h v-E g) n
$$


Where, $\mathrm{h}$ known as Planck constant, $v$ is defined as frequency, $\alpha$ referred as absorbance, $\lambda$ represents the wavelength of absorption and $\mathrm{n}$ represents electronic transition occurred in various forms.

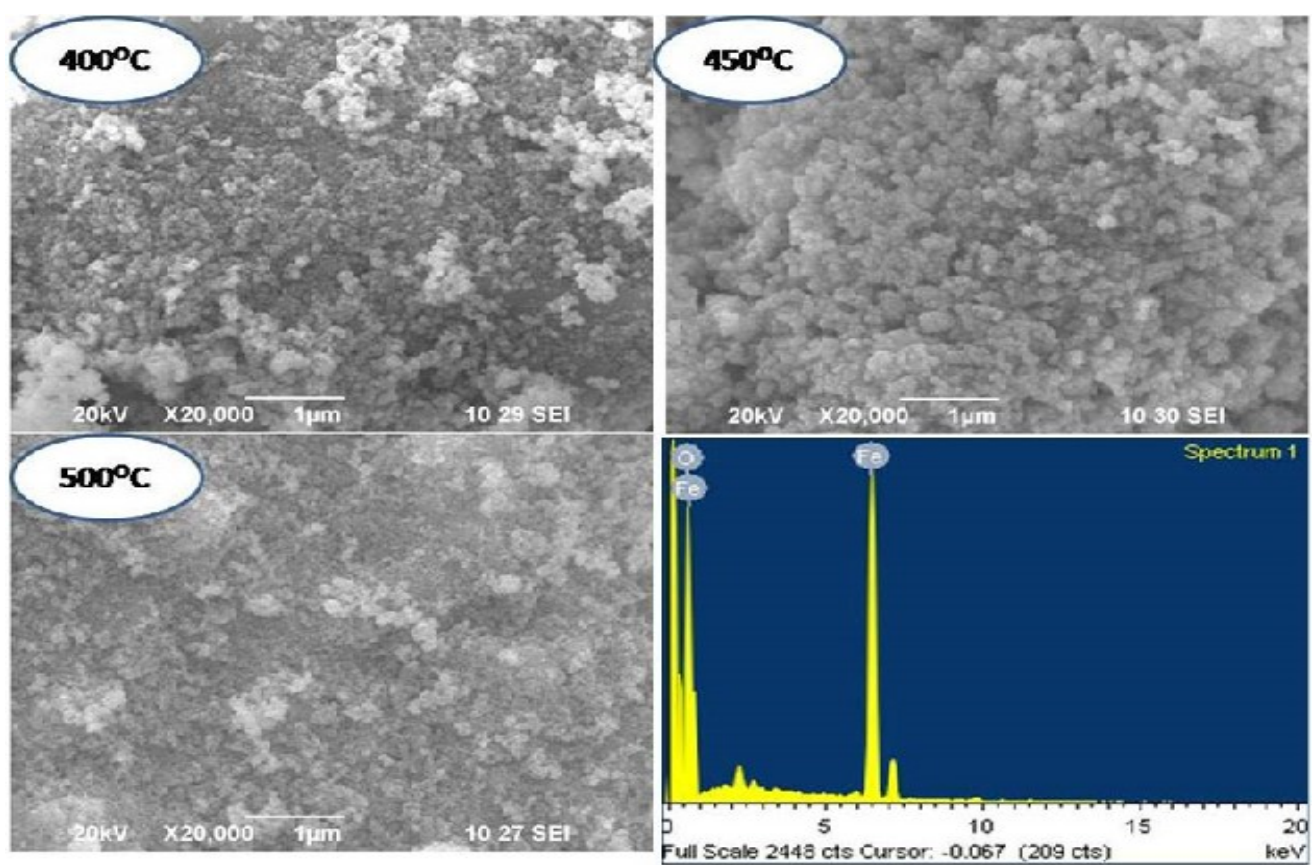

Fig.-2: (a, b, c) SEM images of FeO Nanoparticles at Different Temperatures (d) EDAX study of FeO Nanoparticles

The optical direct bandgap of $\mathrm{FeO}$ nanoparticles was $2.8,2.7,2.6 \mathrm{eV}\left(400^{\circ} \mathrm{C}, 450^{\circ} \mathrm{C}\right.$, and $\left.500^{\circ} \mathrm{C}\right)$. The absorption is generally inversely proportional to the nanoparticles' bandgap value. As seen from Fig.-3(a), if the temperature increases, on the other hand, bandgap values decreased. If the size of the particles is also smaller, the quantum confinement effect is found to be close to the electron's wavelength. Therefore, the reduction in the confining dimension separates the energy levels until the nano-scale range reduces the size of a particle, and these increases or enlarges the bandgap and eventually increases the energy of the bandgap. Because with a decrease in size, the bandgap and wavelength have inversely related to each other the wavelength decreases and the emission of blue radiation is the proof. In the present study, the estimated bandgap of $450^{\circ} \mathrm{C}$ and $500^{\circ} \mathrm{C}, 2.7 \& 2.6 \mathrm{eV}$, respectively. This value is slightly higher than the annealing temperature at $400^{\circ} \mathrm{C}$, which indicates the reduced particle size of synthesized materials.

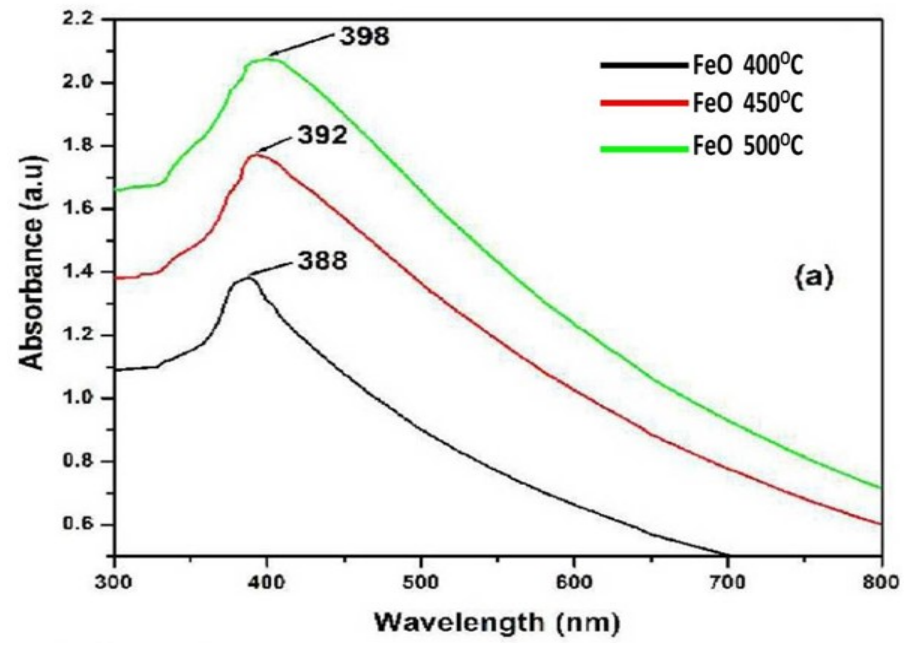

Fig.-3: UV Visible Spectra of FeO Nanoparticles at $400^{\circ} \mathrm{C}, 450^{\circ} \mathrm{C}$, and $500^{\circ} \mathrm{C}$ 
RASĀYAN J. Chem.

Vol. 14 | No. 3 |1985-1989| July - September | 2021

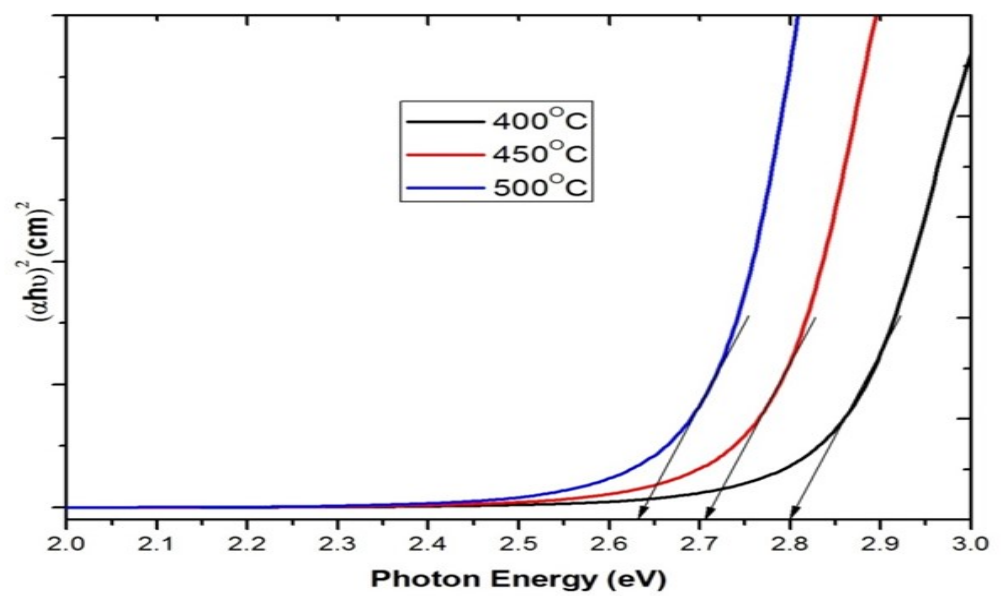

Fig.-3(a): Bandgap Energy of FeO Nanoparticles at $400^{\circ} \mathrm{C}, 450^{\circ} \mathrm{C}$, and $500^{\circ} \mathrm{C}$

CONCLUSION

Nanocrystalline $\mathrm{FeO}$ nanoparticles with a rhombohedral structure successfully synthesized by hydrothermal method. XRD results indicated that with an increase in annealing temperature, the intensity of peaks has increased. The spherical nanoparticle shape with regular morphology is confirmed by SEM. Moreover, the size obtained by SEM, which was in good conformity with the crystalline size computed through XRD. The obtained UV absorbance at 388, 392, and $399 \mathrm{~nm}$ was confined to the blue emission of wavelength. The edge of the optical bandgap moves towards the blue wavelength region, which can be attributed at higher temperatures to the decreasing bandgap of the $\mathrm{FeO}$ nanoparticles. In the future, the $\mathrm{FeO}$ nanoparticle can be considered being a suitable material for fabricating photovoltaic devices, gas sensors, and magnetic materials.

\section{REFERENCES}

1. M. Malakootian, K. Kannan, M.A. Gharaghani, A. Dehdarirad, A. Nasiri, Y.D. Shahamat and H. Mahdizadeh, Journal of Environmental Chemical Engineering, 7, 103457(2019), https://doi.org/10.1016/j.jece.2019.103457

2. K. Kannan, M.H. Sliem, A.M. Abdullah, K.K. Sadasivuni and B. Kumar, Catalysts, 10, 549(2020), https://doi.org/10.3390/catal10050549

3. K. Pradeeswari, A. Venkatesan, P. Pandi, K. Karthik, K.V. Hari Krishna and R. Mohan Kumar, Mater. Res. Express 6, 105525(2019), https://doi.org/10.1088/2053-1591/ab3cae

4. S. Laurent, D. Forge, M. Port, A. Roch, C. Robic, L.V. Elst and R.N. Muller Chemical Reviews, 108, 2064(2008), https://doi.org/10.1021/cr068445e

5. S. Wu, A. Sun, F. Zhai, J. Wang, W. Xu, Q. Zhang and A.A. Volinsky, Materials Letters, 65, 1882(2011), https://doi.org/10.1016/j.matlet.2011.03.065

6. G. Salazar-Alvarez, M. Muhammed and A.A. Zagorodni, Chemical Engineering Science, 61, 4625(2006), https://doi.org/10.1016/j.ces.2006.02.032

7. W. $\mathrm{Wu}, \mathrm{Q} . \mathrm{He}$ and C. Jiang, Nanoscale Research Letters, 3, 397(2008), https://doi.org/10.1007/s11671-008-9174-9

8. F.C. Nalle, R. Wahid, I.O. Wulandari and A. Sabarudin, Rasayan J. Chem, 12, 14(2019) http://dx.doi.org/10.31788/RJC.2019.1214082

9. R. Sun, J. Gao, G. Wu, P. Liu, W. Guo, H. Zhou, J. Ge, Y. Hu, Z. Xue, H. Li, P. Cui, X. Zheng, Y. $\mathrm{Wu}, \quad$ G. Zhang and X. Hong, Cell Reports Physical Science, 1, 100118(2020) https://doi.org/10.1016/j.xcrp.2020.100118

10. K. Sharma, I. Katyal, A. Srivastava, V. Raghavendra Reddy and A. Gupta, (2020) Synthesis and Characterization of $\mathrm{GaO}(\mathrm{OH})-\mathrm{FeO}(\mathrm{OH})$ Nanorod Composite Prepared via Hydrothermal Method, In: V.K. Jain, S. Rattan and A. Verma, (eds) Recent Trends in Materials and Devices. Springer Proceedings in Physics, 256. Springer, Singapore, https://doi.org/10.1007/978-981-15$\underline{8625-5 \quad 10}$

[RJC-6092/2020] 